\title{
Common Genetic Variant of INSIG2 Gene rs7566605 Polymorphism Is Associated with Severe Obesity in North India
}

\author{
Jai Prakash ${ }^{1,2}$, Balraj Mittal ${ }^{3}$, Apurva Srivastava $^{1}$, Shally Awasthi ${ }^{2}$, \\ Pranjal Srivastava ${ }^{4}$ and Neena Srivastava ${ }^{{ }^{1}}$
}

\begin{abstract}
${ }^{1}$ Department of Physiology, King George's Medical University, Lucknow, Uttar Pradesh, India; ${ }^{2}$ Department of Pediatrics, King George's Medical University, Lucknow, Uttar Pradesh, India; ${ }^{3}$ Department of Genetics, Sanjay Gandhi Postgraduate Institute of Medical Sciences, Lucknow, U.P., India; ${ }^{4}$ Darbhanga Medical College and Hospital

Near Karpuri Chowk Benta Laheriasarai Darbhanga Bihar 846003, India
\end{abstract}

Received 5 March 2016; revised 16 April 2016; accepted 26 April 2016

\begin{abstract}
Background: Obesity is a very common disorder resulting from an imbalance between food intake and energy expenditure, and it has a substantial impact on the development of chronic diseases. The aim of this study was to examine the association of INSIG2 (rs7566605) gene polymorphism with obesity and obesity associated phenotypes in North Indian subjects. Methods: The variants were investigated for association in 642 obese and non-obese individuals. The genotyping of INSIG2 (rs7566605) single nucleotide polymorphism was analyzed by the TaqMan allelic discrimination protocol. Results: A significant association was observed for INSIG2 (rs7566605) single nucleotide polymorphism with obesity and obesity-related phenotypes. Furthermore, a significant relationship was found between the rs7566605 and insulin, homeostasis model of assessment-insulin resistance, the percentage of body fat, fat mass, leptin, and adiponectin. Conclusion: The present study observed significant association between INSIG2 (rs7566605) single nucleotide polymorphism and obesity, as well as obesityassociated phenotypes in North Indian population. DOI: 10.18869/acadpub.ibj.21.4.261
\end{abstract}

Keywords: INSIG2, Body mass index, Insulin, Insulin resistance, Polymorphism

Corresponding Author: Neena Srivastava

Department of Physiology, King George's Medical University, Lucknow, Uttar Pradesh, India; Tel.: (+91-941) 5024024; Fax: (+91-552) 2257539;

E-mail: neenasrivastavakgmc@gmail.com

\section{INTRODUCTION}

$\mathrm{O}$ besity results from an disparity among food intake and energy consumption and is a major risk factor for many chronic diseases of adulthood such as type 2 diabetes and coronary heart disease $^{[1,2]}$. Although recent estimates have reported that $>12 \%$ of the entire population is overweight or obese $^{[3]}$, the results of twin and adoption studies have strongly supported the impact of genetics on the variation of obesity ${ }^{[4,5]}$, as well as the heritability of body mass index (BMI) ${ }^{[6-8]}$.

In a genome-wide association study, Herbert and coworkes $^{[9]}$ identified a single nucleotide polymorphism (SNP) (rs7566605) upstream of the insulin-induced gene 2 (INSIG2) and observed a significant association between SNP (rs7566605) and increased BMI. On the other hand, Talbert et al. ${ }^{[10]}$ found a correlation in some of the INSIG2 variants, but not with rs7566605, with the adiposity and biochemical indicators of glucose homeostasis. An association between rs7566605 and obesity has also been reported in different ethnic groups ${ }^{[9,11-13]}$, though these associations have not supported by some studies ${ }^{[14-16]}$. Furthermore, no relationship was observed in the Indian population ${ }^{[17,18]}$. Thus, the association between rs7566605 in the INSIG2 gene and obesity remains controversial.

The SNP rs7566605 is located at 10-kb upstream of the transcription start site of the insig 2 and has 
no known function. INSIGI encodes an endoplasmic reticulum membrane protein that regulates cholesterol $^{[19]}$ and glucose homeostasis ${ }^{[20]}$. INSIG2 is a $21.5-\mathrm{kb}$ gene located on chromosome $2 \mathrm{q} 14$ and encodes INSIG2 protein, which has been functionally related to lipid metabolism by the inhibition of cholesterol and fatty acid synthesis ${ }^{[21,22]}$.

Sterol response element-binding protein (SREBP) is an endoplasmic reticulum membrane bound protein that prevents the proteolytic activation of another protein, in response to cholesterol or insulin ${ }^{[21]}$. This protein resides in the endoplasmic reticulum where it binds to SREBP cleavage-activating protein to inhibit it from convoying SREBPs to the Golgi apparatus ${ }^{[22]}$. Ultimately, INSIG2 inhibits SREBP from stimulating cholesterol synthesis as SREBP cannot be treated and triggered by the Golgi enzymes. These functional effects of INSIG2 gene have also been observed in mice ${ }^{[22,23]}$. Animal data signifies the role of INSIG2 in the regulation of cholesterol in rats ${ }^{[24]}$. However, such observations have not been established in human populations ${ }^{[15,18,25,26] \text {. }}$

The prevalence of hypercholesterolemia has been shown that to be associated with CC homozygotes of rs7566605; however, the SNP rs7566605 was not related to the levels of total cholesterol, high density lipoprotein cholesterol (HDL-C), or triacylglycerol ${ }^{[27]}$. Data mapping of quantitative trait loci in mice for obesity and obesity-related traits and their response to high-fat diet have shown the linkage of the INSIG2 gene with fat depots and serum cholesterol levels ${ }^{[28]}$.

To confirm the above reported findings, we examined the association of rs7566605 polymorphism with obesity defined by BMI and obesity-associated phenotypes; particularly with systolic blood pressure, diastolic blood pressure, serum concentrations of glucose, insulin, and with a surrogate measure of insulin resistance, i.e. the homeostasis model assessment (HOMA) index of insulin resistance. The percentage of body fat, fat mass, total cholesterol, high density lipoprotein cholesterol (HDL-C), low density lipoprotein cholesterol (LDL-C), very low density lipoprotein cholesterol, triglyceride, leptin, and adiponectin were also examined in obese and nonobese individuals from Lucknow, India.

\section{MATERIALS AND METHODS}

\section{Patients}

All individuals participated in the present study were of North Indian origin and belonged to the states of Delhi, Haryana, Jammu and Kashmir, Himachal Pradesh, Uttar Pradesh, Punjab, and Uttarakhand, and those who were not of North Indian origin were excluded. The population was homogeneous with regard to ethnic background, as described in our previous study ${ }^{[29]}$. Prior to the experiments, an informed written consent was taken from each participant, and the identity of all the participants was kept confidential. The study was carried out with the approval of local ethics committee at King George's Medical University Lucknow, Uttar Pradesh, India, and the study protocol was conformed to the ethical guidelines of the 1975 Declaration of Helsinki.

All participants were subjected to a careful screening program that included the assessment of a detailed personal and family history, physical examination, determination of anthropometric measurements, and biochemical profiles. BMI was measured for all the participants. After screening of 821 subjects, we selected 642 cases on the basis of strict inclusion/exclusion criteria.

\section{Inclusion and exclusion criteria for obese and non- obese subjects}

The inclusion criteria for the subjects were having North India origin, having the age of 20-42 years at time of interview, as well as $B M I \geq 30 \mathrm{~kg} / \mathrm{m}^{2}$ for obese and BMI 18.5-29.99 kg/m ${ }^{2}$ for non-obese cases. Subjects who did not fulfil the inclusion criteria and those with congenital and mental disorders, as well as endocrine disorders such as myxoedema, Cushing's syndrome and metabolic disorders like diabetes mellitus, cardiovascular disease, congestive heart failure, and pregnant women were excluded. In total, 309 obese subjects (BMI $\geq 30)$ and 333 non-obese cases $(\mathrm{BMI}<30)$ were enrolled in the study. The participants were selected from general population in Lucknow City (Uttar Pradesh, India).

\section{Biochemical parameters}

Blood samples $(5 \mathrm{ml})$ were collected from obese and non-obese individuals after an overnight fasting. Within one hour of collection, the samples were centrifuged at room temperature for three min to obtain plasma/serum, frozen in aliquots and then stored at $-80^{\circ} \mathrm{C}$ until analysis. Commercial enzymatic test kits (ERBA Diagnostics Mannheim GmbH, Germany) were used to determine HDL-C, triglyceride concentrations, and total cholesterol. LDL-C was calculated by the Friedewald formula (LDL-C=total cholesterol-HDL-C-triglyceride/5 mg/dL). The inter-assay coefficient of variation was $<5.0 \%$ for HDL-C and $<2.5 \%$ for triglycerides ${ }^{[30]}$. Adiponectin was assayed with enzyme-linked immunosorbent assay method. Insulin and leptin levels were determined by enzyme-linked radio immunosorbent assay (Linco Research Inc., USA). The inter-assay coefficient of 
variation for the insulin assay was $5.7 \%{ }^{[31]}$. The intraassay coefficient of variation for leptin was 3.4 to $8.3 \%$, and the inter-assay coefficient of variation was 3.0 to $6.2 \%$. Samples were assayed in duplicate, and the limits of detection and linearity for the leptin radioimmunoassay were 0.5 and $100 \mathrm{ng} / \mathrm{ml}^{[32]}$.

The degree of insulin sensitivity/resistance was calculated according to the HOMA, which is a good index for assessing insulin sensitivity/resistance. Based on HOMA, insulin resistance was calculated as described previously ${ }^{[33]}$. The fasting glucose concentration was measured by glucose oxidaseperoxidase method ${ }^{[34]}$. A body fat analyzer (TanitaTBF-310, Japan) was used to assess the percentage of body fat (fat mass). The body fat analyzer had previously been validated based on bioelectrical impedance ${ }^{[35]}$.

\section{Genotyping and quality control}

INSIG2 (rs7566605) genotyping was performed by the means of TaqMan allelic discrimination protocol (Applied Biosystems, Foster City, CA, USA). Genotype distributions confirmed Hardy-Weinberg equilibrium (HWE, $P>0.05$ ) in the non-obese healthy individuals. Genotype calling from real-time PCR data was performed using an algorithm called "best cycle genotyping algorithm". The quality of the assignment of individual samples to clusters was determined on the basis of silhouette values ${ }^{[36]}$.

\section{Statistical analysis}

The independent samples $t$-test was used for two independent groups of obese and non-obese subjects to verify whether the means for two groups are significantly different or not. Genotype and allele distributions were compared between obese and nonobese subjects using Chi-squared test $\left(\mathrm{X}^{2}\right)$. The independent segregation of alleles was tested for the HWE by comparing the observed genotype frequencies with the expected genotype frequencies $\left(\mathrm{X}^{2}\right.$ test). For case-control studies, differences in genotype distributions were calculated using different models like $\log$ additive, recessive, and dominant model (adjusted for age and sex).

The differences among the three groups (genotypes) were assessed by one-way ANOVA for continuous variables, and variables were given as the mean $\pm \mathrm{SD}$. The association of genotype of INSIG2 variant (rs7566605) with obesity-associated phenotypes was performed with regard to different genetic models such as additive, dominant, and recessive model. Different models are used to ensure that the effect of genotype is due to the genetic variation or due to the other factors. ANOVA was used to analyze the correlation of obesity-associated phenotype between the genotypes. The statistical power of the study $(>80 \%)$ was calculated by QUANTO 1.1 software with regards to the study type (case-control), disease prevalence (prevalence of obesity), and the frequency of the minor allele in the control population at the level of significance 0.05 . All analyses of association between genotypes and phenotypes were conducted using SPSS (ver. 15), and $P<0.05$ was considered statistically significant.

\section{RESULTS AND DISCUSSION}

Anthropometric, biochemical and clinical characteristics of the subjects are provided in Table 1. Fasting insulin, HOMA index, the percentage of body fat, fat mass, leptin, and adiponectin show significant difference between the groups, while fasting sugar did not differ between the obese and non-obese individuals.

The SNP is polymorphic with minor allele frequencies of $\leq 27 \%$, and the studied SNP followed HWE. The results of regression analysis are presented in Table 2. The analyzed genotypic data expressed that INSIG2 (rs7566605) SNP was significantly associated with the increased risk of obesity $(P \leq 0.001)$. C allele was significantly associated with the risk of obesity $(P \leq 0.001)$. The INSIG2 (rs7566605) showed an association with different obesity-associated phenotypes such as insulin, HOMA index, the percentage of body fat, fat mass, leptin, and adiponectin in both obese and non-obese subjects (Table 3).

The role of INSIG2 variant (rs7566605) as a determining factor for development of obesity was investigated in a sample of 642 obese and non-obese individuals belonging to the north of India. In contrast to Kumar et al. ${ }^{[17]}$, a significant association was found between INSIG2 variant (rs7566605) with obesity. Herbert et al. ${ }^{[9]}$ also reported a significant association between INSIG2 genetic variant (rs7566605) and obesity, as assessed by a $\mathrm{BMI} \geq 30 \mathrm{~kg} / \mathrm{m}^{2}$ in different populations, including Western European ancestry, African-Americans, and children. However, in the Nurses' Health Study cohort, the absence of such association suggested that the SNP may have variable effects on different populations.

The association between INSIG2 genetic variant (rs7566605) and obesity has been reported in some studies ${ }^{[12,13,37]}$, but this association was not replicated in others ${ }^{[11,15,16]}$. However, the association was controversial in Asian populations ${ }^{[27,38]}$, except for Japanese population ${ }^{[18]}$. Most importantly, no 
Table 1. Clinical characteristics of study participants

\begin{tabular}{|c|c|c|c|}
\hline Variable & $\begin{array}{c}\begin{array}{c}\text { Obese subjects } \\
(\mathrm{n}=309)\end{array} \\
\end{array}$ & $\begin{array}{c}\begin{array}{c}\text { Non-obese subjects } \\
(\mathrm{n}=333)\end{array} \\
\end{array}$ & $\begin{array}{c}P \\
\text { value } \\
\end{array}$ \\
\hline Age (Year) & $36.78 \pm 2.39$ & $35.44 \pm 2.15$ & 0.916 \\
\hline $\begin{array}{l}\text { Gender } \\
\quad \text { Male }(\%) \\
\text { Female }(\%)\end{array}$ & $\begin{array}{l}153(49.5) \\
156(50.5)\end{array}$ & $\begin{array}{l}194(58.3) \\
139(41.7)\end{array}$ & \\
\hline $\begin{array}{l}\text { Weight }(\mathrm{kg}) \\
\text { BMI }\left(\mathrm{kg} / \mathrm{m}^{2}\right) \\
\text { WC }(\mathrm{cm}) \\
\text { HC }(\mathrm{cm}) \\
\text { WHR }(\mathrm{cm} / \mathrm{cm}) \\
\text { SBP }(\mathrm{mm} \mathrm{Hg}) \\
\text { DBP }(\mathrm{mm} \mathrm{Hg})\end{array}$ & $\begin{array}{c}79.03 \pm 14.18 \\
33.49 \pm 3.57 \\
102.30 \pm 12.39 \\
105.38 \pm 11.09 \\
0.97 \pm 0.10 \\
128.39 \pm 15.19 \\
86.23 \pm 8.05\end{array}$ & $\begin{array}{c}68.92 \pm 13.10 \\
25.05 \pm 3.37 \\
95.67 \pm 11.05 \\
100.83 \pm 9.17 \\
0.95 \pm 0.08 \\
120.51 \pm 11.68 \\
80.76 \pm 7.68\end{array}$ & $\begin{array}{r}0.001 \\
<0.001 \\
<0.001 \\
<0.001 \\
0.015 \\
<0.001 \\
0.027\end{array}$ \\
\hline $\begin{array}{l}\text { Insulin sensitivity } \\
\text { F glucose }(\mathrm{mg} / \mathrm{dl}) \\
\text { F insulin }(\mathrm{mU} / \mathrm{ml}) \\
\text { HOMA index } \\
\text { Body fat }(\%) \\
\text { FM }(\mathrm{kg}) \\
\text { LPT }(\mathrm{mg} / \mathrm{ml}) \\
\text { ADP }(\mu \mathrm{g} / \mathrm{mL})\end{array}$ & $\begin{array}{c}109.23 \pm 15.94 \\
14.99 \pm 9.73 \\
4.15 \pm 2.87 \\
37.28 \pm 6.166 \\
30.60 \pm 8.33 \\
21.13 \pm 4.34 \\
6.52 \pm 1.88\end{array}$ & $\begin{array}{c}109.64 \pm 18.62 \\
10.27 \pm 6.01 \\
2.83 \pm 1.83 \\
27.86 \pm 6.12 \\
20.60 \pm 8.16 \\
14.73 \pm 6.59 \\
7.81 \pm 1.61\end{array}$ & $\begin{array}{r}0.065 \\
<0.001 \\
<0.001 \\
<0.001 \\
<0.001 \\
<0.001 \\
<0.001\end{array}$ \\
\hline $\begin{array}{l}\text { Lipid profile } \\
\text { T cholesterol (mg/dl) } \\
\text { HDL-C }(\mathrm{mg} / \mathrm{dl}) \\
\text { Triglyceride }(\mathrm{mg} / \mathrm{dl}) \\
\text { LDL-C }(\mathrm{mg} / \mathrm{dl}) \\
\text { VLDL-C }(\mathrm{mg} / \mathrm{dl})\end{array}$ & $\begin{array}{c}213.54 \pm 35.72 \\
42.82 \pm 7.13 \\
130.28 \pm 28.88 \\
151.28 \pm 30.44 \\
26.06 \pm 5.78\end{array}$ & $\begin{array}{r}161.71 \pm 44.69 \\
46.30 \pm 10.16 \\
107.12 \pm 19.57 \\
99.68 \pm 37.08 \\
25.03 \pm 4.14\end{array}$ & $\begin{array}{r}0.003 \\
0.001 \\
0.008 \\
<0.001 \\
0.008\end{array}$ \\
\hline
\end{tabular}

Data were presented mean \pm SD. BMI, body mass index; WC, waist circumference; HC, hip circumference; WHR, waist-to-hip ratio; SBP, systolic blood pressure; DBP, diastolic blood pressure; F glucose, fasting glucose; F Insulin, fasting insulin; HOMA index, homeostasis model assessment index; FM, fat mass; LPT, leptin; ADP, adiponectin; T Cholesterol, total cholesterol; HDL-C, high density lipoprotein cholesterol; LDL-C, low density lipoprotein cholesterol; VLDL-C, very low density lipoprotein cholesterol. ${ }^{*} \mathrm{BMI} \geq 30,{ }^{* *} \mathrm{BMI}<30$.

relationship was observed between rs7566605 and BMI or the measures of obesity in two separate studies, using different cohorts of Indian population ${ }^{[17,18]}$.

Minor allele frequency was around $0.27 \%$ in the present study, which is comparable to the frequency reported in a previous study on Indian population ${ }^{[17]}$. The CC genotype and $\mathrm{C}$ allele were significantly associated with obesity in north India, as reported before $^{[9,11-13]}$. In contrast to a previous study on Indian population $^{[17]}$, we observed a significant association with obesity. This discrepancy may be that Kumar et $a{ }^{[17]}$ used two different cohorts, one with three linguistic lineages (Indo-European, Dravidian, and Tibeto-Burman) and the other with coronary artery disease cases and controls. Smith et al. ${ }^{[18]}$, recruited type two diabetic case and controls. In contrast to these studies, the present study has been done on nondiseased individuals of north Indian origin.

On account of the genetic diversity in different populations, the extent of linkage disequilibrium among the genetic variants is likely to vary, which may be one of the most important reasons for the reported inconsistent findings. In the present study, we selected only individuals of the North Indian origin, and all of them were free from any kind of disease.

The influence of INSIG2 rs7566605 on variation in other anthropometric measures, including systolic blood pressure, diastolic blood pressure, fasting insulin, HOMA index, the percentage of body fat, fat mass, leptin, adiponectin, and lipid profile were analyzed in this study. We observed significant association with fasting insulin, HOMA index, percentage of body fat, and fat mass. Significant mean differences were also observed among INSIG2 rs7566605 genotypes for leptin and adiponectin in obese and non-obese study participants. According to the Cervino et al. ${ }^{[23]}$, INSIG2 might be associated with fat mass, as INSIG2 was recognized the upstream of several obesity-related genes in the transcriptional network. Another polymorphism, INSIG2 -102G/A, in 
Table 2. Genotype and allele frequency of INSIG2 rs7566605 gene polymorphism in obese and non-obese subjects

\begin{tabular}{lcccc}
\hline $\begin{array}{l}\text { INSIG2 rs756665 gene } \\
\text { polymorphism }\end{array}$ & $\begin{array}{c}\text { Obese subjects } \\
\boldsymbol{n}^{\boldsymbol{a}}(\boldsymbol{\%})\end{array}$ & $\begin{array}{c}\text { Non-obese subjects } \\
\boldsymbol{n}^{\boldsymbol{a}}(\boldsymbol{\%})\end{array}$ & $\begin{array}{c}\text { OR } \\
\mathbf{9 5 \%} \mathbf{C I})\end{array}$ & $\begin{array}{c}\boldsymbol{P} \\
\text { value }\end{array}$ \\
\hline Genotype & & & & \\
GG & $139(44.98)$ & $197(59.16)$ & Reference & Reference \\
GC & $135(43.69)$ & $123(36.94)$ & $1.56(1.12-2.16)$ & 0.008 \\
CC & $35(11.33)$ & $13(3.90)$ & $3.82(1.95-7.48)$ & $<0.001$ \\
Allele & & & \\
G & $413(66.83)$ & $517(77.63)$ & Reference & Reference \\
C & $205(33.17)$ & $149(22.37)$ & $1.74(1.36-2.22)$ & $<0.001$ \\
\hline
\end{tabular}

$n^{a}=$ the number of individuals; Total number of obese (309) and non-obese subjects (333) (for genotype). Total number of chromosomes in obese (618) and non-obese subjects (666) (for alleles)

high linkage disequilibrium with rs7566605, is associated with obesity and with adipogenesis through SREBP1 activation ${ }^{[26,39]}$. The $-102 \mathrm{G} / \mathrm{A}$ polymorphism has been anticipated as the functional polymorphism of INSIG2 since it seems to influence the level of INSIG2 expression. Dipple et al. ${ }^{[40]}$ suggested that $\mathrm{C}$ alleles of INSIG2 likely influence fat metabolism in relation to physical activity, accommodating the complication within biological networks, and genotype-phenotype correlation. Orkunoglu-Suer and co-workers ${ }^{[37]}$ reported that the rs7566605 $\mathrm{C}$ allele is significantly associated with increased fat in female subjects. This elevation may be related to greater insulin sensitivity, which mediates through an increase in free fatty acid synthase and may also alter with INSIG2 genotypes. The finding has particularly interesting in regard to our results for the associations of rs7566605 genotypes with fat and insulin.

The INSIG2 has a role in the regulation of fat metabolism and insulin resistance ${ }^{[41,42]}$. Meanwhile, rs7566605 SNP presents approximately 10-kb upstream from INSIG2; therefore, it may affect the transcriptional activity of INSIG2. INSIG2 is expressed ubiquitously. It was down-regulated by insulin in the liver and involved in fatty acid synthesis $^{[22,43]}$.

It has previously been shown that plasma adiponectin level could be influenced by body fat ${ }^{[30]}$. In the present study, plasma adiponectin levels differ significantly among the SNP rs7566605 genotypes in obese and non-obese participants, which indicates the genetic effect of this polymorphism not only on obesity but also on body fat. The observed associations with fasting plasma insulin and HOMA index further supports this possibility. In a previous animal study, adiponectin-knockout mice on a high-salt diet developed obesity-associated phenotype like hypertension, which was ameliorated by adiponectin intervention ${ }^{[44]}$. Adiponectin reduced circulating fatty acid levels via enhanced fatty acid oxidation and reduced fatty acid synthesis ${ }^{[45]}$, so it may associate with the increased risk of obesity-associated phenotype, most especially, hypertension through its adverse effects on fatty acid metabolism.

Leptin is an endocrine hormone that inhibits food intake and increases energy expenditure by acting on the hypothalamus ${ }^{[46]}$. In the present study, the SNP rs7566605 genotypes were significantly associated with plasma leptin levels. Leptin plays a major role in the body fat storage through the regulation of food intake and total body energy consumption, and its circulating levels correlate closely with both the BMI and the total amount of body fat ${ }^{[47]}$. INSIG2 also intermediates feedback control of cholesterol synthesis $^{[21]}$, though serum total cholesterol, HDL-C, triglycerides, LDL-C, and very low density lipoprotein cholesterol were not significantly different among genotypes, but it is possible that INSIG2 is associated with obesity as it affects lipid metabolism.

In summary, our study indicates that rs 7566605 in the upstream region of the $I N S I G 2$ gene may influence the risk of obesity and the development of obesityassociated phenotypes. Therefore, the genetic effects of the INSIG2 gene on obesity and obesity-associated phenotypes such as fat mass, insulin, adiponectin, and lipids can be clarified by further studies with the new putative functional variant. Further, these effects may strengthen our understanding toward the role of this gene in susceptibility to obesity and obesity-associated phenotypes, which may help to explain metabolic and cardiovascular dysfunction.

\section{ACKNOWLEDGMENTS}

The authors acknowledge the Indian Council of Medical Research, New Delhi, for the financial support to carry out this research work.

CONFLICT OF INTEREST. None declared. 
Table 3. Physiological parameters and genotypic classes for INSIG2 rs7566605 gene polymorphism in obese and non-obese subjects

\begin{tabular}{|c|c|c|c|c|c|c|c|c|}
\hline \multirow[b]{2}{*}{ Variable } & \multicolumn{3}{|c|}{ Obese subjects } & \multirow[b]{2}{*}{$\begin{array}{c}P \\
\text { value }\end{array}$} & \multicolumn{3}{|c|}{ Non-obese subjects } & \multirow[b]{2}{*}{$\begin{array}{c}P \\
\text { value }\end{array}$} \\
\hline & $\begin{array}{c}\mathbf{A A} \\
(\mathbf{n}=\mathbf{1 3 9})\end{array}$ & $\begin{array}{c}\text { AG } \\
(\mathbf{n}=\mathbf{1 3 5})\end{array}$ & $\begin{array}{c}\text { GG } \\
(\mathbf{n}=35)\end{array}$ & & $\begin{array}{c}\text { AA } \\
(\mathbf{n}=197)\end{array}$ & $\begin{array}{c}\mathbf{A G} \\
(\mathbf{n}=\mathbf{1 2 3}) \\
\end{array}$ & $\begin{array}{c}\text { GG } \\
(\mathbf{n}=13)\end{array}$ & \\
\hline BMI & $30.82 \pm 0.63$ & $34.26 \pm 1.64$ & $41.13 \pm 3.43$ & $<0.001$ & $22.91 \pm 2.69$ & $27.98 \pm 0.95$ & $29.82 \pm 0.08$ & $<0.001$ \\
\hline SBP (mm Hg) & $126.98 \pm 11.19$ & $128.79 \pm 12.72$ & $125.66 \pm 11.65$ & 0.267 & $119.55 \pm 10.25$ & $121.55 \pm 12.27$ & $120.77 \pm 8.78$ & 0.284 \\
\hline $\mathrm{DBP}(\mathrm{mm} \mathrm{Hg})$ & $83.77 \pm 6.91$ & $85.48 \pm 7.30$ & $86.83 \pm 7.78$ & 0.070 & $78.15 \pm 5.51$ & $80.07 \pm 6.97$ & $82.36 \pm 8.84$ & 0.016 \\
\hline \multicolumn{9}{|l|}{ Insulin sensitivity } \\
\hline F glucose (mg/dl) & $110.48 \pm 21.19$ & $108.58 \pm 15.75$ & $110.38 \pm 18.22$ & 0.675 & $107.64 \pm 15.07$ & $111.84 \pm 16.84$ & $108.55 \pm 17.94$ & 0.071 \\
\hline F insulin $(\mathrm{Mu} / \mathrm{ml})$ & $13.90 \pm 3.36$ & $14.62 \pm 3.63$ & $19.65 \pm 2.81$ & 0.004 & $8.83 \pm 3.90$ & $11.91 \pm 3.14$ & $12.41 \pm 3.70$ & $<0.001$ \\
\hline HOMA Index & $4.09 \pm 1.48$ & $3.78 \pm 1.61$ & $5.83 \pm 1.37$ & $<0.001$ & $2.39 \pm 1.45$ & $3.40 \pm 1.73$ & $3.49 \pm 1.05$ & $<0.001$ \\
\hline Body fat (\%) & $36.23 \pm 5.48$ & $37.91 \pm 6.74$ & $38.19 \pm 6.53$ & 0.025 & $26.93 \pm 5.85$ & $29.03 \pm 5.85$ & $30.76 \pm 5.85$ & 0.002 \\
\hline $\mathrm{FM}(\mathrm{kg})$ & $28.85 \pm 6.54$ & $31.16 \pm 7.89$ & $32.25 \pm 9.68$ & 0.002 & $18.95 \pm 6.75$ & $22.84 \pm 9.55$ & $24.46 \pm 7.61$ & $<0.001$ \\
\hline LPT (mg/ml) & $19.22 \pm 5.45$ & $22.59 \pm 8.80$ & $23.06 \pm 5.88$ & $<0.001$ & $12.63 \pm 5.39$ & $17.55 \pm 6.99$ & $19.87 \pm 6.91$ & $<0.001$ \\
\hline $\mathrm{ADP}(\mu \mathrm{g} / \mathrm{mL})$ & $6.14 \pm 2.02$ & $6.29 \pm 2.13$ & $6.94 \pm 1.57$ & 0.002 & $7.34 \pm 1.77$ & $8.02 \pm 1.42$ & $8.10 \pm 1.44$ & $<0.001$ \\
\hline \multicolumn{9}{|l|}{ Lipid Profile } \\
\hline T Cholesterol (mg/dl) & $156.64 \pm 35.71$ & $167.28 \pm 42.48$ & $150.64 \pm 29.68$ & 0.094 & $147.48 \pm 20.37$ & $148.55 \pm 25.93$ & $141.55 \pm 18.00$ & 0.560 \\
\hline HDL-C (mg/dl) & $38.21 \pm 8.72$ & $39.68 \pm 8.97$ & $37.01 \pm 8.43$ & 0.184 & $41.25 \pm 10.90$ & $42.21 \pm 12.26$ & $41.77 \pm 11.32$ & 0.769 \\
\hline Triglyceride (mg/dl) & $113.30 \pm 19.77$ & $116.83 \pm 21.95$ & $112.07 \pm 19.06$ & 0.269 & $105.07 \pm 17.53$ & $105.29 \pm 18.52$ & $110.82 \pm 18.49$ & 0.534 \\
\hline LDL-C (mg/dl) & $118.49 \pm 27.18$ & $124.21 \pm 30.88$ & $113.59 \pm 23.84$ & 0.083 & $106.17 \pm 22.45$ & $107.91 \pm 27.39$ & $111.80 \pm 12.07$ & 0.631360 \\
\hline VLDL-C (mg/dl) & $22.66 \pm 3.95$ & $23.37 \pm 4.39$ & $22.41 \pm 3.81$ & 0.269 & $21.01 \pm 3.51$ & $21.06 \pm 3.70$ & $22.16 \pm 3.70$ & 0.534 \\
\hline
\end{tabular}

Data were presented mean \pm SD. BMI, body mass index; SBP, systolic blood pressure; DBP, diastolic blood pressure; F glucose, fasting glucose; F Insulin, fasting insulin; HOMA Index, homeostasis model assessment index; FM, fat mass; LPT, leptin; ADP, adiponectin; T Cholesterol, total cholesterol; HDL-C, high density lipoprotein cholesterol; LDL-C, low density lipoprotein cholesterol; VLDL-C, very low density lipoprotein cholesterol. 


\section{REFERENCES}

1. Swinburn BA, Sacks G, Hall KD, McPherson K, Finegood DT, Moodie ML, Gortmaker SL. The global obesity pandemic: shaped by global drivers and local environments. The Lancet 2011; 378(9793): 804-814.

2. Popkin BM, Adair LS, Ng SW. Global nutrition transition and the pandemic of obesity in developing countries. Nutrition reviews 2012;70(1): 3-21.

3. Siddiqui MZ, Donato R. Overweight and obesity in India: policy issues from an exploratory multi-level analysis. Health Policy and Planning 2015. doi: 10.1093/heapol/czv105.

4. Min J, Chiu DT, Wang Y. Variation in the heritability of body mass index based on diverse twin studies: a systematic review. Obesity reviews 2013; 14(11): 871882.

5. Stunkard AJ, Sørensen TI, Hanis C, Teasdale TW, Chakraborty R, Schull WJ, Schulsinger F. An adoption study of human obesity. The new england journal of medicine 1986; 314(4):193-198.

6. Bell CG, Walley AJ, Froguel P. The genetics of human obesity. Nature reviews genetics 2005;6(3): 221-234.

7. Farooqi IS, O'Rahilly S. New advances in the genetics of early onset obesity. International journal of obesity 2005; 29(10): 1149-1152.

8. Dosaev T, Prakash J, Livshits G. Contribution of body composition components and soft-tissue biochemical factors to genetic variation of body mass index (BMI) in an ethnically homogeneous population. American journal of human biology 2014; 26(6): 760-767.

9. Herbert A, Gerry NP, McQueen MB, Heid IM, Pfeufer A, Illig T, Wichmann HE, Meitinger T, Hunter D, Hu FB, Colditz G, Hinney A, Hebebrand J, Koberwitz K, Zhu X, Cooper R, Ardlie K, Lyon H, Hirschhorn JN, Laird NM, Lenburg ME, Lange C, Christman MF. A common genetic variant is associated with adult and childhood obesity. Science 2006; 312(5771): 279-283.

10. Talbert ME, Langefeld CD, Ziegler JT, Haffner SM, Norris JM, Bowden DW. INSIG2 SNPs associated with obesity and glucose homeostasis traits in Hispanics: the IRAS Family Study. Obesity 2009; 17(8): 1554-1562.

11. Hall DH, Rahman T, Avery PJ, Keavney B. INSIG-2 promoter polymorphism and obesity related phenotypes: association study in 1428 members of 248 families. BMC medical genetics 2006; 7: 83.

12. Lyon HN, Emilsson V, Hinney A, Heid IM, Lasky-Su J, Zhu X, Thorleifsson G, Gunnarsdottir S, Walters GB, Thorsteinsdottir U, Kong A, Gulcher J, Nguyen TT, Scherag A, Pfeufer A, Meitinger T, Brönner G, Rief W, Soto-Quiros ME, Avila L, Klanderman B, Raby BA, Silverman EK, Weiss ST, Laird N, Ding X, Groop L, Tuomi T, Isomaa B, Bengtsson K, Butler JL, Cooper RS, Fox CS, O'Donnell CJ, Vollmert C, Celedón JC, Wichmann HE, Hebebrand J, Stefansson K, Lange C,
Hirschhorn JN. The association of a SNP upstream of INSIG2 with body mass index is reproduced in several but not all cohorts. PLoS genetics 2007; 3(4): e61.

13. Liu YJ, Liu XG, Wang L, Dina C, Yan H, Liu JF, Levy S, Papasian CJ, Drees BM, Hamilton JJ, Meyre D, Delplanque J, Pei YF, Zhang L, Recker RR, Froguel P, Deng HW. Genome-wide association scans identified CTNNBL1 as a novel gene for obesity. Human molecular genetics 2008; 17(12): 1803-1813.

14. Heid IM, Huth C, Loos RJ, Kronenberg F, Adamkova V, Anand SS, Ardlie K, Biebermann H, Bjerregaard P, Boeing H, Bouchard C, Ciullo M, Cooper JA, Corella D, Dina C, Engert JC, Fisher E, Francès F, Froguel P, Hebebrand J, Hegele RA, Hinney A, Hoehe MR, Hu FB, Hubacek JA, Humphries SE, Hunt SC, Illig T, Järvelin MR, Kaakinen M, Kollerits B, Krude H, Kumar J, Lange LA, Langer B, Li S, Luchner A, Lyon HN, Meyre D, Mohlke KL, Mooser V, Nebel A, Nguyen TT, Paulweber B, Perusse L, Qi L, Rankinen T, Rosskopf D, Schreiber S, Sengupta S, Sorice R, Suk A, Thorleifsson G, Thorsteinsdottir U, Völzke H, Vimaleswaran KS, Wareham NJ, Waterworth D, Yusuf S, Lindgren C, McCarthy MI, Lange C, Hirschhorn JN, Laird N, Wichmann HE. Meta-analysis of the INSIG2 association with obesity including 74,345 individuals: does heterogeneity of estimates relate to study design? PLoS genetics 2009; 5(10): e1000694.

15. Vimaleswaran KS, Franks PW, Brage S, Sardinha LB, Andersen LB, Wareham NJ, Ekelund U, Loos RJ. Absence of association between the INSIG2 gene polymorphism (rs7566605) and obesity in the European Youth Heart Study (EYHS). Obesity 2009; 17(7): 14531457.

16. Wiedmann S, Neureuther K, Stark K, Reinhard W, Kallmünzer B, Baessler A, Fischer M, Linsel-Nitschke P, Erdmann J, Schunkert H, Hengstenberg C. Lack of association between a common polymorphism near the INSIG2 gene and BMI, myocardial infarction, and cardiovascular risk factors. Obesity 2009; 17(7): 13901395.

17. Kumar J, Sunkishala RR, Karthikeyan G, Sengupta S. The common genetic variant upstream of INSIG2 gene is not associated with obesity in Indian population. Clinical genetics 2007; 71(5): 415-418.

18. Smith AJ, Cooper JA, Li LK, Humphries SE. INSIG2 gene polymorphism is not associated with obesity in Caucasian, Afro-Caribbean and Indian subjects. The international journal of obesity 2007; 31(11): 17531755.

19. Janowski BA. The hypocholesterolemic agent LY295427 up-regulates INSIG-1, identifying the INSIG-1 protein as a mediator of cholesterol homeostasis through SREBP. Proceedings of the national academy of sciences of the United States of America 2002; 99(20): 12675-12680. 
20. Krapivner S, Chernogubova E, Ericsson M, AhlbeckGlader C, Hamsten A, van 't Hooft FM. Human evidence for the involvement of insulin-induced gene 1 in the regulation of plasma glucose concentration. Diabetologia 2007; 50(1): 94-102.

21. Gong Y, Lee JN, Brown MS, Goldstein JL, Ye J. Juxta membranous aspartic acid in Insig-1 and Insig-2 is required for cholesterol homeostasis. Proceedings of the national academy of sciences of the United States of America 2006; 103(16): 6154-6159.

22. Yabe D, Brown MS, Goldstein JL. Insig-2, a second endoplasmic reticulum protein that binds SCAP and blocks export of sterol regulatory element-binding proteins. Proceedings of the national academy of sciences of the United States of America 2002; 99(20): 12753-12758.

23. Cervino AC, Li G, Edwards S, Zhu J, Laurie C, Tokiwa G, Lum PY, Wang S, Castellani LW, Lusis AJ, Carlson $S$, Sachs AB, Schadt EE. Integrating QTL and highdensity SNP analyses in mice to identify Insig2 as a susceptibility gene for plasma cholesterol levels. Genomics 2005; 86(5): 505-517.

24. Takaishi K, Duplomb L, Wang MY, Li J, Unger RH. Hepatic insig-1 or -2 overexpression reduces lipogenesis in obese Zucker diabetic fatty rats and in fasted/refed normal rats. Proc Natl Acad Sci USA 2004; 101(18):7106-7111.

25. Feng Y, Dong H, Xiang Q, Hong X, Wilker E, Zhang Y, $\mathrm{Xu} \mathrm{X}$. Lack of association between rs7566605 and obesity in a Chinese population. Human genetics 2007; 120(5): 743-745.

26. Krapivner S, Popov S, Chernogubova E, Hellénius ML, Fisher RM, Hamsten A, van't Hooft FM. Insulininduced gene 2 involvement in human adipocyte metabolism and body weight regulation. The journal of clinical endocrinology and metabolism 2008; 93(5): 1995-2001.

27. Oki K, Yamane K, Kamei N, Asao T, Awaya T, Kohno $\mathrm{N}$. The single nucleotide polymorphism upstream of insulin-induced gene 2 (INSIG2) is associated with the prevalence of hypercholesterolaemia, but not with obesity, in Japanese American women. british journal of nutrition 2009; 101(3): 322-327.

28. Cheverud JM, Ehrich TH, Hrbek T, Kenney JP, Pletscher LS, Semenkovich CF. Quantitative trait loci for obesity- and diabetes related traits and their dietary responses to high-fat feeding in LGXSM recombinant inbred mouse strains. Diabetes 2004; 53(12): 33283336.

29. Prakash J, Srivastava N, Awasthi S, Agarwal C, Natu S, Rajpal N, Mittal B. Association of PPAR- $\gamma$ gene polymorphisms with obesity and obesity-associated phenotypes in North Indian population. American journal of human biology 2012; 24(4): 454-459.
30. Prakash J, Mittal B, Awasthi S, Agarwal CG, Srivastava N. Hypoadiponectinemia in obesity: association with insulin resistance. The indian journal of clinical biochemistry 2013; 28(2): 158-163.

31. Prakash J, Mittal B, Awasthi S, Agarwal CG, Srivastava $\mathrm{N}$. K121Q ENPP1/PC-1 gene polymorphism is associated with insulin resistance in a North Indian population. The journal of genetics 2013; 92(3): 571576.

32. Prakash J, Srivastava A, Mittal B, S Awasthi, CG Agarwal, N Srivastava. Association of fasting plasma leptin level with obesity and insulin resistance. International Journal of Biological \& Pharmaceutical Research 2012; 3(4): 560-566.

33. Matthews DR, Hosker JP, Rudenski AS, Naylor BA, Treacher DF, Turner RC. Homeostasis model assessment: insulin resistance and beta-cell function from fasting plasma glucose and insulin concentrations in man. Diabetologia 1985; 28(7): 412-419.

34. Young DS, Pestaner LC, Gibberman V. Effects of drugs on clinical laboratory tests. Clinical Chemistry 1975; 21(5):1D-432D.

35. Jackson AS, Pollock ML, Graves JE, Mahar MT. Reliability and validity of bioelectrical impedance in determining body composition. Journal applied physiology (1985); 64(2): 529-534.

36. Rousseeuw PJ. Silhouettes: a graphical aid to the interpretation and validation of cluster analysis. Computational and applied mathematics 1987; 20: 5365.

37. Orkunoglu-Suer FE, Gordish-Dressman H, Clarkson PM, Thompson PD, Angelopoulos TJ, Gordon PM, Moyna NM, Pescatello LS, Visich PS, Zoeller RF, Harmon B, Seip RL, Hoffman EP, Devaney JM. INSIG2 gene polymorphism is associated with increased subcutaneous fat in women and poor response to resistance training in men. BMC medical genetics 2008; 9: 117.

38. Kuzuya M, Ando F, Iguchi A, Shimokata H. No association between rs7566605 variant and being overweight in Japanese. Obesity 2007; 15(11): 25312534.

39. Fornage M, Papanicolaou G, Lewis CE, Boerwinkle E, Siscovick DS. Common INSIG2 polymorphisms are associated with age-related changes in body size and high-density lipoprotein cholesterol from young adulthood to middle age. Metabolism 2010; 59(8):10841091.

40. Dipple KM1, Phelan JK, McCabe ER. Consequences of complexity within biological networks: robustness and health, or vulnerability and disease. Molecular genetics and metabolism 2001;74(1-2): 45-50.

41. Song MY, Ruts E, Kim J, Janumala I, Heymsfield S, Gallagher D. Sarcopenia and increased muscle adipose 
tissue infiltration in elderly African-American women. The american journal of clinical nutrition 2004; 79(5): 874-880.

42. Zderic TW, Hamilton MT. Physical inactivity amplifies the sensitivity of skeletal muscle to the lipid-induced down regulation of lipoprotein lipase activity. The journal of applied physiology 2006; 100(1): 249-257.

43. Takaishi K, Duplomb L, Wang MY, Li J, Unger RH. Hepatic insig-1 or -2 overexpression reduces lipogenesis in obese Zucker diabetic fatty rats and in fasted/refed normal rats. Proc Natl Acad Sci USA 2004; 101: 71067111.

44. Ohashi K, Kihara S, Ouchi N, Kumada M, Fujita K, Hiuge A, Hibuse T, Ryo M, Nishizawa H, Maeda N, Maeda K, Shibata R, Walsh K, Funahashi T, Shimomura I. Adiponectin replenishment ameliorates obesity-related hypertension. Hypertension 2006; 47(6):1108-1116.

45. Xu A, Wang Y, Keshaw H, Xu LY, Lam KS, Cooper GJ. The fat derived hormone adiponectin alleviates alcoholic and non-alcoholic fatty liver diseases in mice. The journal of clinical investigation 2003; 112(1): 91100.

46. Friedman JM, Halaas JL. Leptin and the regulation of body weight inmammals. Nature 1998; 395(6704): 763770.

47. Fruhbeck G, Jebb SA, Prentice AM. Leptin: physiology and pathophysiology. Clinical physiology 1998; 18:399419. 